\title{
BIBLIOGRAFIA: CAMINHOS DA HISTÓRIA CONTADA E DA HISTÓRIA VIVIDA
}

\section{BIBLIOGRAFÍA: DE CAMINOS ANTIGUOS A LAS FORMAS ACTUALES}

\author{
Eduardo Alentejo - alentejo@oi.com.br \\ Doutor em Ciência da Informação pela Universidade de \\ Brasília (UnB). Professor da Universidade Federal do Estado \\ do Rio de Janeiro (UNIRIO).
}

\begin{abstract}
RESUMO
Introdução: Trata sobre a Bibliografia tendo como referência sua historiografia. Tem por material as bibliografias citadas, os clássicos e os autores que marcaram o desenvolvimento da área.

Objetivo: Visa analisar a bibliografia como sendo campo de interesse científico, buscando responder quais são os caminhos de sua história contada e de sua história vivida que a legitimam como campo de interesses científicos?

Metodologia: A partir do método historiográfico, discorre sobre o estado atual do ensino brasileiro da Bibliografia. Mediante revisão de literatura, explica sua divisão em ramos e discorre sobre sua historiografia de acordo com contornos históricos dos quais envolvem aspectos tecnológicos da produção do conhecimento.
\end{abstract}

Resultados: Explica que a polifonia e a vulgarização acerca de seu campo científico são fenômenos com impactos às atividades intelectuais nacionais. Analisa conceitos que fundamentam e validam a Bibliografia como área do conhecimento. Atualiza e dá continuidade historiográfica da Bibliografia ao acrescentar reflexões sobre as épocas do trabalho bibliográfico na era digital. Os resultados apontam para a evolução da Bibliografia, tanto enquanto produto e serviço, como área científica em constante desenvolvimento.

Conclusões: Através da análise historiográfica, os caminhos da Bibliografia indicam que o campo de estudo é inesgotável, porque a pesquisa sobre o passado de bibliografia acumulada incluem aspectos teóricos que permanecem no tempo atual e sua atualidade expõe muitas possibilidades para o seu futuro. As bibliografias em ambiente Web permitem expandir entendimentos referentes ao acesso e ao uso da informação pela possibilidade de se empregar recursos tecnológicos capazes de aperfeiçoar suas funções sociais de acesso ao conhecimento, em distintos escopos.

Palavras-chave: Ensino no Brasil da bibliografia. Fundamentos da bibliografia. Ramos da bibliografia. Historiografia da bibliografia. Bibliografia na era digital. 


\section{INTRODUÇÃO}

A importância em discorrer sobre Bibliografia no Brasil e a um público com distintos interesses se torna oportuna à breve contribuição disposta neste texto para o campo científico a que se destinou o evento "A arte da Bibliografia".

Uma vez que os entendimentos sobre Bibliografia foram validados por intelectuais em diferentes contornos e contextos históricos ${ }^{1}$, duas consequências se tornaram evidentes: a) a polifonia acerca da Bibliografia; b) a divisão por correntes de pensamento e por ramos que se ocupam o trabalho bibliográfico. Nesse trabalho se analisa a trajetória da Bibliografia tendo como referência sua historiografia que traz no bojo de seus fundamentos científicos o alicerce para o trabalho bibliográfico ${ }^{2}$.

Por motivos óbvios, não se pretendeu esgotar o tema, pois, séculos de 'Bibliografia', do desenvolvimento de recursos tecnológicos da produção de artefatos informativos; a diversidade de materiais, das teorias e métodos acumulados em diversos estudos, quase sempre em torno de associações profissionais e institutos bibliográficos ${ }^{3}$, bem como as obras na área pouco disponíveis nas bibliotecas brasileiras, são marcas à limitação desse estudo.

Assim, a maioria das fontes consultadas foi adquirida no exterior e pelo acesso às bibliotecas, editoras e centros bibliográficos de países

\footnotetext{
${ }^{1}$ Os primeiros teóricos da Bibliografia que se tem notícia surgem no início do Séc. XIX: S. Boulard, com o Traité élémentaire de bibliographie, publicado em 1805 e C. F. Achard, com a obra 'Cours élémentaire de bibliographie, em 1806. A Bibliografia foi consagrada como ciência nos primeiros anos do Séc. XX pela pesquisa do inglês Alfred Willian Pollard em torno dos estudos denominados "Sheakespeare Folios Quartos" em 1909 (FONSECA, 1979). Em 1955 Zoltowski (1955, p. 8) explica que: "mais do que uma simples técnica auxiliar, a Bibliografia é [...] 'uma ciência concreta', que tem como objetivo o recenseamento da produção de livros sob todos os aspectos."

2 O termo 'trabalho bibliográfico' é empregado para se referir às práticas de pesquisa e à elaboração de serviços e produtos bibliográficos, cujas teorias e métodos alicerçam o campo científico da Bibliografia (MALCLÈS, 1950; BELANGER, 1977).

${ }^{3}$ Por exemplo, The Bibliographical Society fundada em 1892 publica o periódico The Library desde 1920 sem interrupções <http://www.bibsoc.org.uk/about>. Institut d'histoire du livre formado por: Biblioteca Pública, Museu da Imprensa de Lyon e mais três Escolas francesas de Biblioteconomia, entre elas a École nationale des chartes <http://ihl.enssib.fr/en/about-the-ihl>.
} 
cuja tradição em Bibliografia é evidente ${ }^{4}$. Considerou-se também consultas a bibliografias brasileiras, tais como: Diccionario bibibliographico de Innocencio Francisco da Silva (1858-1923), Bibliographie brésilienne of Garraux (1898), o Catálogo da Exposição de História do Brasil, publicado em 1881, sob a direção de Ramiz Galvão e o Manual Bibliográfico de Estudos Brasileiros, publicado em 1949 por Rubens Borba de Moraes. Outra fonte consultada foi o catálogo "Livros Raros de Biblioteconomia: a memória científica da Biblioteca Nacional brasileira" (PINHEIRO, 2013).

Além da literatura estrangeira ${ }^{5}$, a revisão de literatura nacional se deu em estudos daqueles que se ocuparam com excelência sobre a Bibliografia: Xavier Placer (1955); Figueiredo e Cunha (1967), Araújo (1969), Fonseca (1972, 1979), Cruz e Beckmann (1995), entre outros.

Embora que, Dunkin (1975) tivesse advogado que qualquer definição sobre bibliografia decorre de uma experiência ou crença pessoal válida, permito-me divergir da maioria dos discursos sobre Bibliografia, desde aqueles percebidos quando em contato com o senso comum e a outros que se pode encontrar na literatura biblioteconômica ${ }^{6}$; pois, em geral, há omissão da funcionalidade da Bibliografia (KATZ, 1992).

Tal discordância decorre de duas constatações: no Brasil o ensino de 'bibliografia' tem sido negligenciado nos cursos de Biblioteconomia; e a vulgarização do termo 'bibliografia' a limita ao

\footnotetext{
${ }^{4}$ A tradição de países no campo da Bibliografia é verificada nas correntes científicas cuja produção e proliferação de livros, sobretudo impressos, marca a história dos livros e das bibliotecas. Destacam-se as correntes: inglesa e francesa das quais se tem notícia dos primeiros conceitos e bases científicas sobre Bibliografia (FREER, 1954; HARMON, 1981; 1998).

${ }^{5}$ Greg (1914), Besterman (1935), Condit (1937), Reuben (1937), Freer (1954), Malclès (1950, 1956), Gaskell (1972), Dunkin (1975), Harmon (1981), Serrai (1994), Reyes-Gómez (2010), entre outros.

${ }^{6}$ Admitindo as funções essenciais de qualquer bibliografia, tal como explicam Placer (1955), Mccrank (1979), Katz (1992), o senso comum se limitada à enumeração de itens numa lista, desconectada do processo de: identificação, verificação, localização e seleção. Assim, tal lista consta obras cujas unidades poucos conseguem acessar.
} 
sentido de produto ${ }^{7}$, destituído de noções sobre controle bibliográfico ${ }^{8} \mathrm{e}$ transmissão material precisa dos livros e multimeios ${ }^{9}$.

Para McCrank (1979), a Bibliografia é de difícil caracterização, pois, nem todos os recursos de descrição ou referência são bibliografias, e muitas compilações são imprecisamente assim intituladas, mesmo no campo da Biblioteconomia.

Serrai (1994) afirma que a polissemia resulta no desfavor ao campo da Bibliografia porque distancia suas funções de seu significado. Referindo-se às funções de uma bibliografia, Beaudiquez (1989, p. 23, tradução nossa) afirma que para se compreender o valor e o significado de Bibliografia é necessário compreender o contexto: "redigir uma bibliografia, consultar uma bibliografia ou planejar uma bibliografia, e outras expressões, escondem realidades diferentes".

Além disso, Harmon (1998) explica que nenhuma discussão sobre bibliografia pode deixar de mencionar sua relação com o aumento da demanda por métodos precisos de comunicação e recuperação de informações relativas às acumulações de registros em que a civilização contemporânea depende.

Nesse contexto, busca-se responder: quais são os caminhos da história contada e vivida que legitimam a Bibliografia como campo de interesse científico? Além da revisão de literatura e relativa propriedade em uma década como docente das disciplinas 'Bibliografia' e 'Controle Bibliográfico', sob o prisma da epistemologia social desenvolvida por Shera e Egan (1975), a análise historiográfica se baseia em estudo exploratório visando à continuidade da Bibliografia.

\footnotetext{
${ }^{7}$ Belanger (1977, p. 99) e Harmon (1981, p. 3) afirmam que o desgaste do termo 'Bibliografia' se deu por não bibliógrafos.

8 Para o grupo de trabalho 'futuro do controle bibliográfico' da Library of Congress (2008, p. 10), rotas de acesso à produção intelectual não se limitam aos catálogos institucionais e nem aos diversos recursos tecnológicos ou serviços bibliográficos existentes, pois, todos constituem meios para o acesso às fontes de informação e não fins, sob os princípios da Bibliografia.

9 Gaskell (1972, p. 3) define a bibliografia por sua materialidade, sendo o propósito a transmissão precisa dos documentos.
} 
Esse texto inicia com reflexões sobre o ensino da Bibliografia no Brasil. E as discussões seguintes decorrem do exame da historiografia com que a Bibliografia é analisada. Por fim, discorre sobre sua aplicação atual.

\section{SOBRE O ENSINO DA BIBLIOGRAFIA NO BRASIL}

Atualmente no Brasil, há trinta e nove cursos de nível superior em Biblioteconomia; eles estão divididos entre universidades federais, estaduais e particulares e distribuídos conforme indica o quadro:

Quadro 1 - Quantidade de cursos de nível superior em Biblioteconomia no Brasil

\begin{tabular}{|l|c|}
\hline \multicolumn{2}{|c|}{ Cursos de Biblioteconomia no Brasil } \\
\hline \multicolumn{1}{|c|}{ Faculdades/Universidades } & Quantidade \\
\hline $\begin{array}{l}\text { Universidade Federais e } \\
\text { Estaduais }\end{array}$ & 26 \\
\hline Faculdades Particulares & 13 \\
\hline Total & 39 \\
\hline
\end{tabular}

Fonte: Conselho Regional de Biblioteconomia (2015).

Ao se considerar o relatório coordenado por Nice Figueiredo (1978) sobre o ensino de Biblioteconomia no Brasil ao fim da década de 1970, do qual avaliou o status quo das escolas brasileiras de Biblioteconomia e Documentação, o País contava com vinte e nove instituições de ensino superior com cursos na área. Comparando com o quadro atual de instituições de ensino superior, primeiro se verifica um aumento em torno de $35 \%$ dos cursos e também uma diminuição substancial do ensino da Bibliografia, aproximadamente $86 \%$.

À época, todos os cursos avaliados possuíam a disciplina 'bibliografia' em suas matrizes curriculares. O ensino da Bibliografia, enquanto disciplina, é praticado atualmente em cinco cursos no País, e está distribuído do seguinte modo: uma disciplina na região sul, duas na região do nordeste, uma na região sudeste e uma na região central do País. Isto é, totalizando cinco disciplinas dedicadas aos estudos da Bibliografia. 
E a despeito da alta concentração dos cursos na região sudeste do País, dos dezessete cursos pesquisados, apenas o curso da UNIRIO oferece disciplina delimitada ao campo de estudos em Bibliografia. Verdade que, um breve exame às matrizes curriculares disponíveis nos sítios de considerável número de cursos de Biblioteconomia, os termos 'bibliografia' e 'controle bibliográfico' aparecem ocasionalmente, principalmente no âmbito das disciplinas dedicadas à 'Catalogação' ou 'Fontes de Informação'.

Contudo, não se pode verificar nenhum conteúdo que se ocupa aos estudos da Bibliografia, tal como os entendimentos encontrados em autores como McCrank (1979), Harmon (1998), Alfaro Lopez (2011), Reyes Gómez (2010) ou Varry (2011) cujos estudos apontam que à Bibliografia um corolário foi adicionado a sua teoria: o 'ambiente bibliográfico ideal' é aquele em que a informação cada vez mais diversificada e completa se localiza nos fundamentos do trabalho bibliográfico ${ }^{10}$.

Como sugestão de um futuro estudo, se poderia analisar o porquê de a Bibliografia ter sido quase dizimada das matrizes curriculares dos cursos brasileiros de nível superior em Biblioteconomia. Um ponto de partida à questão reside no conceito de sincretismo da Biblioteconomia brasileira, explicado por Alentejo e Pinheiro (2014). Para os autores, o resultado da combinação de teorias e práticas de diferentes escolas e nacionalidades tanto justapôs quanto colocou em oposição variadas combinações de vertentes sobre o pensar e o fazer em Biblioteconomia.

Nesse contexto, se o Século XIX foi marcado pelas bibliografias monumentais, de caráter nacional, tal como a França que publicou, por exemplo, a Bibliographie de la France (1811) e La France littéraire por

\footnotetext{
${ }^{10}$ A atualidade do trabalho bibliográfico pode ser verificada em dimensões como a que trata a seção de Bibliografia do Congresso IFLA em agosto de 2015 com o tema transformações da Bibliografia Nacional em relação ao depósito legal diante dos recursos eletrônicos (e-legal deposit). Fonte: http://conference.ifla.org/ifla81/node/1015.
} 
Quérard (1827-1864) e Portugal lançou o Diccionario bibibliographico de Innocencio Francisco da Silva $(1858-1923)^{11}$; a bibliografia brasileira começou apenas em 1883, com o Diccionario bibliographico brasileiro, escrito por Sacramento Blake (1883-1902) e com a obra Bibliographie brésilienne de Garraux de 1898.

Se desde o início do Século XIX, o campo da Bibliografia nos denominados países desenvolvidos oferecia à produção científica nacional serviços e produtos bibliográficos especializados e de valor ao desenvolvimento técnico-científico; foi na metade do século que o Brasil dispôs de consultor estrangeiro para 'atualizar' e auxiliar na criação de centro bibliográfico dedicado à informação científica com a ambição institucional em desenvolver ciência e tecnologia brasileiras ${ }^{12}$.

Se considerarmos que, por exemplo, as bibliografias nacionais correntes do Reino Unido, da França, da Alemanha, Espanha e Portugal permaneceram em desenvolvimento e hoje estão disponíveis em sítios na Internet, com recursos e serviços de informações aos usuários, e quando olhamos para o passado da bibliografia nacional corrente brasileira, marcada pela descontinuidade, tal como ao que Fonseca (1972) constatou, se verifica que os problemas antes diagnosticados pelo autor ainda vigoram-se aos dias de hoje, o que se pode ressentir pela inexistência da bibliografia nacional corrente e pela duvidosa consistência de serviços e produtos bibliográficos de alcance nacional ${ }^{13}$, e visibilidade internacional.

O enfrentamento à sobrecarga bibliográfica começou tarde no Brasil. E quando também se verifica que o ensino da Bibliografia é

\footnotetext{
${ }^{11}$ Segundo Placer (1955, p. 13), a bibliografia representativa portuguesa foi elaborada por Diogo Barbosa Machado: 'Bibliotheca lusitana'. Em 1808, ela serviu de referência à constituição do acervo da Biblioteca Nacional no Brasil.

${ }^{12} \mathrm{Na}$ década de 1950, H. Coblans foi enviado ao Brasil pela Unesco para estimular um centro bibliográfico nacional; General Report of the Conference on the Improvement of Bibliographical Services. Paris: Unesco House, 1950. Disponível em:

http://unesdoc.unesco.org/images/0012/001270/127057eb.pdf. O relatório final de H. Coblans foi publicado na Revista Ciência da Informação em 1990.

13 "Uma bibliografia nacional geral pobre dá idéia de uma produção intelectual também pobre, já que aquela reflete o estado da cultura do povo que representa" (KOHLER, 1977, p. 188).
} 
colocado à margem na formação de profissionais bibliotecários, que por vezes enfrentam restrições orçamentárias e tecnológicas, a deficiência quanto à inovação bibliográfica reflete 0 atraso que possivelmente se perpetuará. A sistematização do ensino da Bibliografia não seria panaceia, mas, poderia contribuir para melhorar a atual situação.

Os danos decorrentes disso são variados. A ineficiência ou ausência sistemática da bibliografia nacional corrente, geral e especializada, pode afetar setores tais como: saúde, educação, meio ambiente etc. Por exemplo, o estudo do Instituto de Pesquisa Ambiental da Amazônia, em parceria com o Observatório do Código Florestal, se utiliza de pesquisas e estudos científicos para comprovar que as faixas protegidas como Áreas de Preservação Permanente devem ser mais largas do que determina o atual Código Florestal. Uma das conclusões dos especialistas dessa área aponta que o debate sobre código florestal ignorou a produção científica existente, sendo um dos problemas a falta de recursos bibliográficos que permitissem diminuir o tempo e a distância entre a produção do conhecimento ecológico e a tomada de decisão política (LIMA, 2014, p. 5).

Dentre os exemplos brasileiros do abuso do termo 'bibliografia', o caso do Sistema Nacional de Avaliação da Educação Superior (SINAES, 2010) pode ser destacado, onde a expressão "Livros da bibliografia básica", que ocorre no item 3.2.1, do documento avaliativo às bibliotecas universitárias, costuma levar a muitas pessoas com quem tenho contato, a utilizar a mesma expressão em seu cotidiano. Por exemplo, na elaboração de ementas disciplinares, em projetos de pesquisa ou mesmo nas listas sugeridas às bibliotecas, no contexto onde estão inseridas $^{14}$.

\footnotetext{
${ }^{14}$ Uma vez que a expressão 'bibliografia básica' não representa conceito algum e respaldado na literatura especializada, o termo 'básica' a qual se refere o documento avaliativo sugere que diante das limitações do ensino superior brasileiro, há uma lacuna de qualidade de repertórios e dos acervos bibliográficos, localizados nas bibliotecas universitárias do Brasil.
} 
Evidentemente, a polifonia e a vulgarização acerca de seu campo científico não são peculiaridades brasileiras. Ao contrário, países que tradicionalmente são reconhecidos na produção de produtos e serviços bibliográficos, tais como: Itália, Inglaterra e França têm relativas semelhanças.

Pensato (1994, p. 15) afirma que, "longe de denotar riqueza, é o resultado de uma estratificação expressiva das atormentadas vicissitudes léxico-conceituais das disciplinas do livro que por si mesma resulta mais em cumulativas confusões do que em assertividade". Já McCrank (1979) atribui tal vulgarização às áreas de humanas.

Reuben (1937), Belanger (1977), Harmon (1981, 1998) e Varry (2011) explicam que as confusões em seus países com que os acadêmicos, estudantes e professores, cientistas e outros intelectuais fazem entre o que consideram serem termos relacionados à Bibliografia ampliam a polifonia que, usualmente de modo distorcido, perpetua 0 senso comum à vulgarização do termo ${ }^{15}$.

Harmon (1998, p. 1) explica que a palavra 'bibliografia' é empregada por muitos acadêmicos no limite de significar 'lista de livros'. Já Varry (2011) relaciona a falta de tradição de estudos em bibliografia material na atualidade em função da noção vigente de que 'bibliografia' se limita a repertório; ou como aponta Fonseca (1979, p. 29) busca de informação bibliográfica ${ }^{16}$.

Placer (1955) explica que essencialmente uma bibliografia se caracteriza pela sistematização de inventários sobre um ou vários assuntos, distintos de uma lista ou relação sem método que evidencie as etapas do trabalho bibliográfico e seus princípios: verificação, probidade intelectual e planejamento. Pois, "bibliografia incompleta,

\footnotetext{
${ }^{15}$ Fonseca (1979, p. 30) ao contestar a acanhada concepção do trabalho bibliográfico que inclui a pesquisa bibliográfica no contexto do ensino brasileiro, propôs o termo antibibliografia para se opor à limitação da Bibliografia como simples técnica ou simples ciência auxiliar.

${ }^{16}$ Fonseca (1979, p. 29) explica que vige uma confusão entre busca por informação com pesquisa bibliográfica. Ao senso comum, esta última não passa de busca por livros e artigos sobre um determinado assunto ou autor, limitando-se a mera cópia de dados obtidos em fontes de referências como catálogos, bibliografias e enciclopédias.
} 
vaga ou canhestramente relacionada, é quase tão inútil quanto bibliografia nenhuma" (PLACER, 1955, p. 7).

Sob o prisma dos autores consultados, é incontestável a importância da bibliografia para as atividades intelectuais, como no caso da comunicação científica. Indutivamente, o exame do propósito, do alcance e do arranjo bibliográficos é estratégico à avaliação e à classificação das bibliografias. Pois, além de revelar sua natureza e funcionalidade, evidencia sua orientação pela qual elas são produzidas e disponibilizadas. Destaco algumas orientações onde a Bibliografia pode ser aplicada. Esse recurso permite, por exemplo, guiar o profissional à execução do trabalho bibliográfico, desde o planejamento até a sua materialização.

a) Bibliografia orientada para a Comunicação Científica;

b) Bibliografia orientada para o Controle Bibliográfico;

c) Bibliografia orientada para o Mercado Editorial;

d) Bibliografia orientada para a elaboração de Produtos e Serviços de informação;

e) Bibliografia orientada para a Documentação. ${ }^{17}$

Tais aplicações atendem às mais variadas orientações de empreendimento em Bibliografia. Esse modo pragmático de observar sua aplicação é fluído. Pois, as possíveis aplicações se cruzam e se transformam diante do emprego das tecnologias emergentes, e nessas interações se ampliam (SIMÓN DÍAZ, 1971), por exemplo, ao gerar noções temporais como: retrospectiva, seriada ou corrente.

Na dinâmica do uso da informação nos sistemas, onde o trabalho bibliográfico se vincula, necessidades informacionais são moldadas à própria natureza da produção bibliográfica (SHERA; EGAN, 1975), tornando complexa a arquitetura dos sistemas que visam efeitos de

\footnotetext{
${ }^{17}$ Não cabe nesse momento explicar essa classificação, mas sim, tal como concebem Reuben (1937) Simón Díaz (1971), perceber que ao longo do tempo as aplicações foram possíveis e à medida que as contingências históricas ampliam temas e aplicações da Bibliografia sob os recursos tecnológicos, se verifica que o campo científico sobre Bibliografia é ilimitado em termos de expansão de teorias, métodos e aplicações.
} 
controle bibliográfico, probidade intelectual (PLACER, 1955, p. 8) e acesso à informação (CASE, 2012, p. 8).

Em relação aos sistemas bibliográficos, o Grupo de Trabalho sobre Controle Bibliográfico da 'Library of Congress' (WORKING GROUP ON THE FUTURE OF BIBLIOGRAPHIC CONTROL, 2008, p. 10, tradução nossa) explica que diferentes comunidades de prática bibliográfica têm crescido em torno de diferentes tipos de recursos: coleções de livros e periódicos; arquivos; artigos de periódicos; e objetos de museu, imagens e materiais sonoros. "Como esses recursos e outros se tornam cada vez mais acessíveis via Web, toda separação das comunidades de prática que os geram não é mais desejável, sustentável, ou funcional".

O diagnóstico que o grupo tece sobre controle bibliográfico referese cada vez mais à questão de gestão de relações entre obras, nomes, conceitos, descrições de objetos e comunidades. A consistência de inscrição em qualquer ambiente único, como o catálogo da biblioteca, é "cada vez menos significativa do que a capacidade de fazer conexões entre ambientes, como da Amazon para o WorldCat, para o Google, para o PubMed, para a Wikipedia, com acervos de bibliotecas, mas, servindo como um nó nesta teia de conectividade" (WORKING GROUP ON THE FUTURE OF BIBLIOGRAPHIC CONTROL, 2008, p. 10-11, tradução nossa).

Se no ambiente da informação em rede, o controle bibliográfico não pode continuar a ser visto como sendo limitado a catálogos de bibliotecas ou aos serviços de resumos e índices. Isso sugere que no contexto do trabalho bibliográfico, os serviços e produtos bibliográficos passaram a abarcar temas que são de interesse ao campo da Bibliografia, tais como: sistemas de informação federados; busca federada; sistema de coleta de metadados (harverting) (FERREIRA; SOLTO, 2006) e inteligência coletiva (LANKES et al., 2007), preservação digital (CRIADO, 2015) e arquitetura da informação (ALENTEJO, 2014b). 
No entanto, toda e qualquer produção intelectual que se processe pelo trabalho bibliográfico se estabelece na relação tempo-espaço, e por isso, resulta na tentativa de se colmatar as falhas quanto à divulgação da pesquisa técnico-científica, artística e literária através das bibliografias (BASTO, 1999, p. 63). Nesse sentido, seu alcance reflete um movimento a partir do âmbito local para o nacional e evidentemente para o internacional, quando se pensa a visibilidade da produção intelectual de um determinado país ou grupos de países (ALFARO LOPEZ, 2011).

Como professor, percebo uma lacuna de conhecimento para avançar nos estudos sobre Bibliografia que podem contribuir para a inovação bibliográfica na 'era digital' nos versionamentos Web ${ }^{18}$. Apresenta-se a seguir as bases conceituais sobre Bibliografia e os caminhos com os quais marcam seus fundamentos, ramos e, claro, a diversidade de entendimentos em seu próprio campo científico.

\section{CAMINHOS DA BIBLIOGRAFIA}

Pensato (1994, p. 35-36) reconhece três visões vigentes sobre Bibliografia: a) termo banalizado, desprovido de conceito; b) visão instrumental mediana, compartilhada entre estudiosos de qualquer campo cultural; c) visão erudita e profissional, compartilhada por aqueles que estudam as técnicas, os procedimentos, a teoria, a história, a estrutura em seu campo científico e seus resultados.

Nessa direção, a noção de Bibliografia que vige em muitos dos entendimentos, dos quais tenho testemunhado evoca, mesmo que de forma vaga, uma das suas primeiras concepções. Em geral, se percebe

\footnotetext{
18 Palestra proferida, no 3ํ. Colóquio Internacional de Arquitetura da Informação e Multimodalidade, Brasília, DF, o autor explica que a evolução das plataformas Web tem facilitado à geração e à ampliação de produtos e serviços bibliográficos, sobretudo, de bibliotecas digitais, tal como ocorre no modelo 5S desenvolvido por Gonçalves (2004). Nessa perspectiva, a Epistemologia Social, disciplina desenvolvida Shera e Egan (1975), concebe o campo da Bibliografia para o desenvolvimento de sistemas automatizados de recuperação da informação e para a medição do ciclo informacional.
} 
àquela empregada por Gabriel Naudé, secretário e bibliotecário do Cardeal Mazarino, em sua obra 'Bibliographia politica' de 1633 da qual designava exatamente uma relação de livros. Após a concepção de Naudé, o mesmo ocorreu pelo emprego dado pelo francês Louis Jacob de Saint-Charles em seus dois trabalhos: "Bibliographia gallica universalis y la Bibliographia parisina", publicados entre 1645 e 1654 (REYES-GÓMEZ, 2010).

De acordo com Simón Diaz (1971, p. 22), o termo empregado por Naudé tinha por objetivo adquirir um caráter diferenciado das coleções de obras conservadas nas bibliotecas cujos instrumentos de guarda eram submetidos a algum tipo de norma, e conhecidos como: 'Catalogus', 'Bibliotheca', 'Index', 'Registrum' ou 'Repertorium'.

No início dos anos 1950, Freer (1954, p. 1-13) documentou desde 1678 cerca de 50 definições sobre 'bibliografia' e constatou que a maioria delas, vinte e quatro, surgiu após 1900, poucas concordando entre si e muitas discordando completamente uma das outras.

No entanto, o termo 'bibliografia' é definido com precisão em sua base etimológica, pelo agrupamento dos vocábulos em grego Biblion, livro; Graphé, descrição. Nesse sentido, significa descrição dos livros. E ainda, pela junção das palavras do grego Biblion (livro) e Graphaein (escrever) resultando no termo Bibliographos para significar copistas de manuscritos (HARMON, 1998, p. 2).

O exame historiográfico da Bibliografia foi explorado por vários teóricos da área em distintas épocas, tanto para estabelecer as relações bibliográficas produzidas de acordo com as contingências históricas em que cada época as revelou quanto para as analisarem em termos conceituais, por exemplo, Besterman (1935), Freer (1954), Malclès (1956), Harmon (1981, 1998) e Reyes Gómez (2010).

Ao se referir à obra "Bibliographie Instructive" de 1763, do bibliotecário francês DeBure, Condit (1937, p. 564) explica que, provavelmente, foi pela primeira vez que o termo Bibliografia foi empregado sob o espectro profissional da disciplina, o bibliógrafo. 
Embora que o autor considere a existência do trabalho bibliográfico desde a Antiguidade, ele explica que o conceito de Bibliografia foi concebido quase quatro séculos antes por Conrad Gesner e foi batizado durante o Século XVIII por DeBure.

No entanto, a entrada da Bibliografia para o campo de investigação científica é relativamente recente (HARMON, 1998; REYES-GÓMEZ, 2010). Sob a denominação de "nova bibliografia", o campo de estudos foi explorado ao que a literatura denominou por ramos da bibliografia analítica, nos início do Século $X X$, com as pesquisas de Sir Walter Wilson Greg (1914), Alfred William Pollard, and Ronald Brunless Mckerrow (HARMON, 1981, 1998).

Contudo, Harmon (1998, p. 13) explica que decorrente de uma necessidade essencial para colocar ordem e fornecer acesso à massa de documentos, a bibliografia surgiu como um elemento primordial nesse processo de ordenamento e transmissão bibliográficos.

Muitas definições foram dadas para descrever o que bibliografia é e faz, mas, ainda há discordância entre profissionais sobre o significado de bibliografia e sobre a precisão de suas funções ${ }^{19}$. Desse modo, 0 estudo da Bibliografia é situado em dimensões e estas situadas em ramos com que se empreende o trabalho bibliográfico. O que se analisa a seguir.

\subsection{Correntes e Ramos da Bibliografia}

Num sentido amplo, Bibliografia conota o estudo dos livros e outros materiais gráficos (MALCLÈS, 1956; FIGUEIREDO; CUNHA, 1967). Especificamente, o estudo envolve a análise detalhada destes materiais como recursos primários, com foco na produção física,

\footnotetext{
${ }^{19}$ Harmon $(1981$, p. 13,65 ) avalia os discursos elaborados por especialistas de ambos os ramos da Bibliografia e constata que por vezes, bibliógrafos compreendem como científico apenas o ramo analítico; as bibliografias enumerativas e sistemáticas são também consideradas como produto científico porque sua natureza e os usos produzem o efeito de transferir a informação do produtor ao usuário final.
} 
aspectos materiais e estruturais, publicação e divulgação de informações úteis para determinadas comunidades de leitores e a longevidade de um livro ou outros materiais (MCCRANK, 1979, p. 175).

Assim, o objetivo principal da bibliografia é localizar materiais gráficos, facilitando o acesso aos conteúdos e ao conhecimento sobre o livro e a outros suportes multimeios. Esse objetivo decorre sob os três tipos de análises:

a) Análises físicas: estudos de livros, e outros materiais como objetos físicos. Esse tipo de análise situa as Bibliografias denominadas: descritivas, históricas, textuais e críticas, científicas ou materiais,

b) Análise de assunto: visa localizar cada item em relação a outros itens sobre o mesmo ou outros assuntos. O produto é o arranjo de itens por dispositivos como cabeçalhos de assunto ou a classificação de assuntos,

c) Análise por autor e/ou título: visa localizar cada item em relação aos outros itens com o mesmo ou outro autor ou título. O produto é o arranjo por autor ou por título dos itens ou por listas de itens (PLACER, 1955; MALCLÈS, 1963; GASKELL, 1972; HARMON,1998; REYES-GÓMEZ, 2010).

Segundo Harmon (1998), no início do Século XX, a bibliografia era percebida dentro da literatura especializada por duas formas de escopos: foco no conteúdo e nas propriedades físicas. Reuben (1937, p. 67) separa a Bibliografia sob dois aspectos: a 'bibliografia intelectual' e a 'bibliografia material', onde a primeira se caracteriza por favorecer acesso aos conteúdos registrados, e a segunda por proporcionar estudos em torno das características extrínsecas do livro tais como: sua produção, preços, edições etc.

Dois modos interessantes de se dimensionar 0 trabalho bibliográfico ocorrem pela análise das correntes da bibliografia (REYESGÓMEZ, 2010), e por sua classificação em ramos (HARMON, 1981, 1998). 
Na primeira abordagem, há a divisão por duas grandes correntes: a tradicional ou continental e a anglo-saxônica. Reyes-Gómez (2010, p. 57-61) também analisa outra corrente, a dos tratadistas italianos. $\mathrm{Na}$ segunda, os dois ramos são classificados do seguinte modo: o enumerativo, ou sistemático, que enfatiza a função secular das bibliografias, e o analítico que engloba aspectos que superam a limitação estritamente bibliográfica de transmissão de ideias.

Já os tratadistas italianos consideram artificial tais divisões. Sob o ponto de vista da história do livro e da tipografia na Itália, buscam uma visão integrada das análises que caracterizam o trabalho bibliográfico como uma ciência com aspectos multidisciplinares e sociais ${ }^{20}$; entre outros autores dessa corrente se destacam: Pensato (1994) e Serrai (1994).

Quanto à organização e à estruturação, Harmon (1998, p. 4) apresenta a classificação que melhor permite a visualização dos escopos de interesse dos bibliógrafos, por ramos. Tendo em vista os dois ramos da corrente inglesa, as bibliografias são classificadas como analíticas ou críticas e bibliografias enumerativas ou sistemáticas ${ }^{21}$. As primeiras se ocupam essencialmente dos aspectos materiais dos itens analisados e as demais envolvem arranjos ordenados com o foco nos conteúdos.

O ramo Analítico ou Crítico resulta da corrente anglo-saxônica da 'nova bibliografia'. Refere-se ao estudo de materiais informativos em relação a como são feitos, do exame da colação e descrição de livros e não livros (GASKELL, 1972; WILLIAMSON, 1967). Assim, é o estudo da arte dos livros e outros itens como objetos físicos. Portanto, é inteligível à materialidade do suporte.

\footnotetext{
${ }^{20}$ Quanto à natureza da Bibliografia, Serrai (1994) elabora classificação da qual a bibliografia social é compreendida nas disciplinas: comunicação, histórica da cultura, história do livro e da comunicação em massa.

${ }^{21}$ Vale o destaque $\mathrm{d}$ a corrente norte-americana que concebe um terceiro ramo denominado por histórico (MCCRANK, 1979).
} 
O ramo Enumerativo ou Sistemático decorre da corrente tradicional do estudo da Bibliografia que se caracteriza pela elaboração de lista de materiais com alguma reconhecida relação com outro material. Este pode ser definido como o estudo de livros ou outros materiais gráficos como meio para transmitir ideias (HARMON, 1998, p. 4-6). Portanto, é inteligível ao conteúdo do livro e de outros suportes multimeios.

O campo da Bibliografia percebido assim em ramos permite a análise das dimensões com as quais princípios, métodos de investigação e técnicas são determinados e aplicados à pesquisa e ao trabalho bibliográfico.

Harmon (1998) e Reyes-Gómez (2010), por exemplo, advogam que essas análises permitem a amplitude conceitual que imputa à Bibliografia muitos significados de acordo com as várias adjetivações ou qualificações que se somam ao termo, por exemplo: enumerativa, sistemática, analítica, crítica (HARMON, 1998), descritiva (WILLIAMSON, 1967; BELANGER, 1977), histórica (MCCRANK, 1979), textual (BELANGER, 1977, p. 99), e estatística (FONSECA, 1979).

Os pressupostos teóricos da Bibliografia podem ser representados pela figura a seguir que apresenta os fundamentos da Bibliografia:

Figura1 - Fundamentos teóricos da Bibliografia

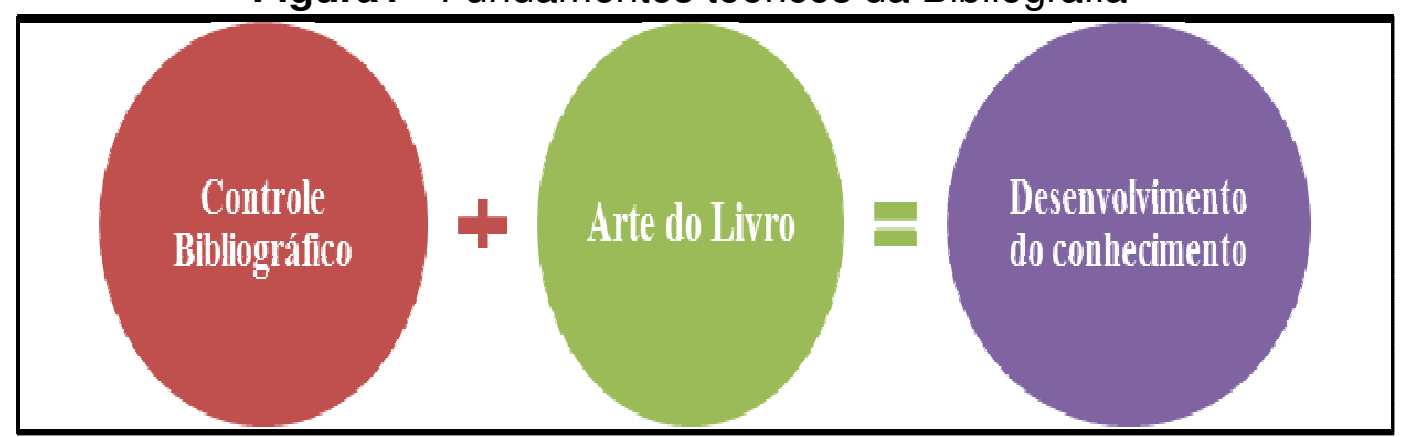

Fonte: O autor.

Considerando estes elementos como fundamentos do trabalho bibliográfico, a Bibliografia tem por interesses: a informação disponível na literatura para produzir efeitos de repertório em termos de controle 
bibliográfico, favorecendo a elaboração de recursos para o avanço do conhecimento e o próprio aspecto físico do suporte como objeto de conhecimentos sobre a História dos Livros, das Bibliotecas, da Tipografia, do Sistema Editorial e outros aspectos que se interessa a Bibliologia, a Bibliofilia e a Comunicação Científica, entre outras áreas.

O grau de interação que permite identificar a que se destina o empreendimento bibliográfico pode ser medido conforme o gráfico a seguir:

Gráfico 1- Interação dos pressupostos teóricos da Bibliografia

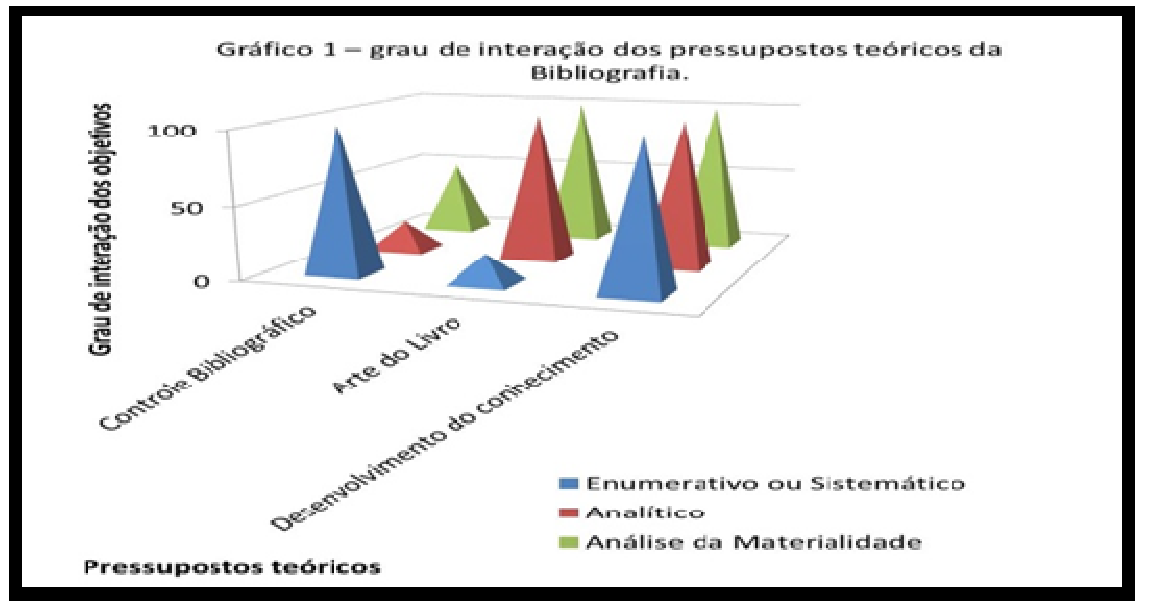

Fonte: Adaptado de Alentejo (2014a).

Conforme demonstra o gráfico, o grau de interação do ramo Enumerativo ou Sistemático com o pressuposto de controle bibliográfico é maior do que o grau relativo à materialidade, a arte do livro. E de modo oposto, o grau de interação com o pressuposto da arte do livro ${ }^{22}$ do ramo analítico é maior em relação ao interesse pelo conteúdo. Em comum, ambos os ramos têm como resultado evidente 0 desenvolvimento do conhecimento.

Os estudiosos da corrente da Bibliografia Analítica ou Crítica entendem que a questão da análise física ou material se baseia em

\footnotetext{
${ }^{22}$ A expressão 'arte do livro' abarca formas de análise física ou material que se ocupa o ramo analítico (HARMON, 1981).
} 
formulações que englobam outros aspectos que superam as bibliografias destinadas essencialmente a viabilizar 0 controle bibliográfico (GASKELL, 1972). O plano material se sobrepõe ao interesse intelectual do conteúdo e do qual os livros comunicam. Todavia, também o considera importante para os estudos descritivos e textuais que investigam as várias cópias ou edições de um determinado item ou de um determinado título de um ou mais autores e ainda, a cópia mais apropriada (HARMON, 1998, p. 83).

Harmon (1981, 1998) e Fonseca (1979) apontam que a Bibliografia se desenvolve como ciência nos trabalhos dos bibliógrafos Sir Walter Wilson Greg, Alfred William Pollard, e Ronald Brunless Mckerrow que a denominaram por 'nova bibliografia'. Em 1927 Ronald Brunless Mckerrow, por exemplo, publica o livro: "Introdução a Bibliografia para alunos de literatura" sendo a primeira tentativa de examinar o uso dos materiais impressos e métodos da época 'elisabetana', demonstrando as questões envolvidas na transmissão do texto desde sua concepção manuscrita até a publicação impressa dessa edição, bem como, as possíveis mudanças ocorridas nas próximas edições (HARMON, 1981, p. 14).

Reyes-Gómez (2010, p. 59-60) explica que as formulações e objetivos que se destinam a 'nova bibliografia' também são conhecidos por Bibliografia Material. E esta é derivada da 'bibliografia tipográfica', expressão criada pelos ingleses na metade do Século XVIII que se ocupava da análise material dos documentos impressos tal como ocorria em determinados catálogos e repertórios ingleses (MCKERROW, 1998). A Bibliografia Material é identificada como a ciência do livro que é o objeto de estudo de distintos pontos de vistas ou interesses, como por exemplo, sua história, produção e descrição (VARRY, 2011).

Nesse cenário, se pode afirmar que enquanto atividade, a Bibliografia é uma das mais antigas profissões exercidas por bibliotecários e bibliógrafos desde a invenção da escrita. Sua história demonstra que ela é persistente e que moldou, durante séculos, sua 
formação enquanto área científica consolidada pelas constantes adaptações às necessidades de mudanças no seio das sociedades (HARMON, 1981, p. 10).

\subsection{Modos de Apresentação da História da Bibliografia}

Malclès (1956), a partir de estudos de Besterman (1935) sobre a evolução da Bibliografia, desenvolveu um modo de visualização por épocas com a qual analisa a trajetória da Bibliografia. A autora apresenta um conceito operacional sobre Bibliografia que a enuncia como sendo o conhecimento de todos os textos impressos ou multigrafados que se fundamenta na pesquisa, na transcrição, na descrição e no arranjo desses textos visando à organização de serviços ou à elaboração de repertórios destinados a facilitar o trabalho intelectual (MALCLÈS, 1956, p. 16).

Sob uma perspectiva epistemológica, Malclès (1956) a concebe como parte da Bibliologia ou da ciência do livro que se propõe a: buscar, identificar, descrever e classificar os documentos impressos com 0 objetivo de criar repertórios que facilitem o trabalho intelectual.

Placer (1955) expande essa noção ao advertir que a 'bibliografia' não se localiza na categoria da simples técnica de catalogação e classificação, pois, seu produto depende dos princípios técnicos da verificação, probidade intelectual e planejamento.

Tal como Placer (1955), Cruz e Beckmann (1995) também conceberam o exame historiográfico para se analisar as bibliografias. As análises desses autores tanto caracterizam a Bibliografia como recurso social de acesso à informação sob a influência da teoria da bibliografia de Shera e Egan ${ }^{23}$ quanto à identificação e avaliação das espécies de bibliografias de acordo com âmbitos de sua aplicação: geral, políticas de informação de alcance nacional, particular, interesse científico e

\footnotetext{
${ }^{23}$ Texto publicado originalmente em 1952 por Shera e Egan.
} 
tecnológico organizacional, e interno (agências bibliográficas e de documentação).

Harmon (1998) adotou a mesma perspectiva historiográfica de Besterman e Malclès e reproduziu parte do que estes sugeriram sobre o que foi concebido sobre as épocas evolutivas da Bibliografia. Contudo, o autor avança em suas análises ao incluir o exame da Bibliografia do ramo Analítico ou Científico, trazendo mais evidências do desenvolvimento da Bibliografia a partir da tradição inglesa.

Reyes Gómez (2010, p. 35, tradução nossa) concebe a evolução semântico-cronológica da Bibliografia, caracterizando o uso do termo por uma ordenação temporal, "desde a mais primitiva terminologia a mais recente, determinada por sua delimitação com a Documentação". O autor constata que a Bibliografia foi percebida como: lista de livros, estudo dos manuscritos, ciência dos livros, ciência das bibliotecas, ciência dos repertórios, parte da Documentação que se ocupa dos registros impressos.

Gaskell (1972) explica que a bibliografia é a ciência da transmissão de documentos e de seus conteúdos, e sua evolução está ligada à história da tecnologia de produção dos livros, bem como de outros materiais. Embora ele inclua todos os tipos de materiais informativos como província do bibliógrafo, o autor explica a história da produção de livros e outros materiais gráficos sob dois grupos históricos relacionados à tecnologia: a) período artesanal, de 1500 a 1800; b) período mecanização em larga escala, de 1800 a 1950.

Nessa perspectiva, e exame das tecnologias de produção de artefatos informativos são de interesse ao trabalho bibliográfico, arguindo em que contextos e como os objetos eram e passaram a ser produzidos.

Ao se examinar a literatura sobre a evolução da Bibliografia, se pode compreender que seu desenvolvimento enquanto campo científico reflete os sistemas de produção, transmissão e uso da informação. 
A historiografia nos mostra que a Bibliografia perpassou do simples trabalho de inventariar como também se ocupou do controle bibliográfico dentro dos sistemas de produção intelectual, não lineares e complexos $^{24}$. Isto é, compreendidos e elaborados em qualquer uma de suas estruturas ou momentos de mudanças sociais, e geralmente de modo concomitante com o avanço tecnológico ${ }^{25}$.

Isso porque, a Bibliografia tem sido um dos recursos empregados para elevar a noção de aleatoriedade caótica dos sistemas frente à noção de caos determinístico (MOREIRA, 1992) e também às noções de explosão bibliográfica que se derivam após o advento da tipografia de Gutenberg (BRADFORD, 1953; CRUZ; BECKMANN, 1995), de caos documentário entre o Século XIX e início do XX com a mecanização da impressão (BRADFORD, 1953; COBLANS, 1957), e da sobrecarga informacional emergente com as Tecnologias da Informação e da Comunicação (SIRKKA HAVU, 2005).

Se os próprios teóricos do campo de pesquisa sobre Bibliografia ampliam seus entendimentos no debate científico, permitam-me supor que a ausência desse debate no Brasil cria uma lacuna que pode levar a muitos colegas ao engano caso pensem que o campo de estudos sobre Bibliografia já está concluído ou definido.

Isso porque, a ampliação do trabalho bibliográfico decorre da incessante e concomitante produção do conhecimento e das tecnologias de sua produção e divulgação da informação, sob o efeito do advento da tipografia no Século XV, e mais recentemente das tecnologias da Informação e da Comunicação dos Séculos XX e XXI, o trabalho bibliográfico foi e continua ininterrupto.

Ao longo do tempo, as unidades do pensamento registrado, o volume de publicações e a variação dos suportes de registros se

\footnotetext{
${ }^{24}$ Sobre sistemas não lineares e complexos: Moreira (1992).

${ }^{25}$ Em seu texto "As We May Think", Vannevar Bush vaticina a noção de hipertexto ao tecer crítica à ordenação linear de sistemas de informação, segundo a qual o pensamento humano por não ser linear busca informação nos sistemas por associação. Fonte: http://www.ps.unisaarland.de/ duchier/pub/vbush/vbush-all.shtml.
} 
multiplicaram exponencialmente, expandindo, assim, o trabalho bibliográfico de modo a constituir novos artefatos informativos como objetos de interesse, baseados nos fundamentos e metodologias da Bibliografia: pesquisa, transcrição, descrição e arranjos.

Por exemplo, de acordo com Shera e Egan (1953, 1975), as áreas de investigação da Bibliografia são essenciais não só para o desenvolvimento de sistemas automatizados de recuperação de informação, mas também para a elaboração de estatísticas sobre a produção, distribuição e utilização de documentos. As que emergiram na década de 1960 lidam essencialmente com a aplicação dos métodos de medição, o que agora é referido como área da 'bibliometria' (FONSECA, 1979; PRITCHARD, 1969).

O trabalho bibliográfico durante os primeiros 400 anos da popularização do livro, a partir de tipografia de Gutenberg, ampliou a Bibliografia e esta teve relação estreita com 0 trabalho da Documentação e que para Paul Otlet e Henri La Fontaine ambos os ramos, da Bibliografia e da Documentação, eram sinônimos (COBLANS, 1957).

A Documentação enquanto ciência passou a vigorar como área independente da Biblioteca, e a Bibliografia se tornou uma das disciplinas que compunha a Documentação, com base na incorporação da recuperação documental de modo sistemático, na cooperação internacional e susceptível às políticas nacionais de cooperação bibliográfica e de alcance internacional.

O fundamento da Documentação pode ser traduzido por uma dinâmica oposta ao que se praticava dentro das bibliotecas; a recuperação da informação ao invés de se dar de forma passiva, isto é, a partir do pedido do usuário, passa a estar disponível para o efeito que enuncia: qual assunto atual está disponível e onde, tornando-se assim a ciência explícita do controle bibliográfico (COBLANS, 1957; FONSECA, 1979; MENOU; GUINCHAT, 1994). 
Todavia, Shera e Egan (1975) desenvolveram a disciplina 'epistemologia social' como um referencial teórico para o estudo da produção, distribuição e utilização de produtos intelectuais processados pelo trabalho bibliográfico. No texto 'Fundamentos de uma teoria da Bibliografia', os autores identificaram uma lacuna no campo da Bibliografia e propuseram a disciplina com referencial teórico para explicitar os âmbitos com os quais o trabalho bibliográfico, os instrumentos bibliográficos e produtos e serviços em Bibliografia são inteligíveis a cada propósito social pelo qual a sociedade empreende para constituir uma das principais tarefas dentro de sistemas informacionais, o acesso à informação.

\section{CAMINHOS DA HISTÓRIA CONTADA E DA HISTÓRIA VIVIDA}

A historiografia da Bibliografia pode ser percebida como um 'álbum de fotografias' que salvaguarda o pensamento humano registrado e que, obviamente, se esgotará no infinito. Logicamente, a história contada é diferente da história vivida, pois, a observação é fator à análise dos fatos que podem explicar a Bibliografia como um campo de interesse científico contínuo.

Nesse contexto, a evolução dos conceitos sobre Bibliografia de acordo com as épocas com as quais o trabalho bibliográfico foi desenvolvido projeta tal categorização histórica que se observa nos estudos de autores como: Besterman (1935) e Malclès (1956); Williamson (1967); Figueiredo e Cunha (1967); Harmon (1981, 1998); Serrai (1994); Reyes Gómez (2010), entre outros.

Segundo Harmon (1998), as funções de bibliografia foram determinadas ao longo do tempo por contextos históricos, por tecnologias de reprodução e disseminação e pelo desenvolvimento do conhecimento. Besterman (1935) e Malclès (1956) aplicam o método historiográfico para analisar a Bibliografia como área científica. A partir destas abordagens, o trabalho bibliográfico pode ser analisado por natureza e utilidade em diferentes fases históricas. 
Harmon (1998) fornece uma divisão de tempo para Bibliografia: 'Começos' que corresponde ao período Pré-tipográfico, Período Médio que corresponde à fase imediata da tipografia e logo, artesanal da bibliografia, Período Moderno, fase tipográfica da mecanização intelectual, e Período contemporâneo.

Malclès (1956) divide o desenvolvimento da bibliografia em etapas de acordo com contornos históricos e suas funções: Pré-história antes do tipo móvel e da Imprensa; Era Erudita - séculos XV e XVI; Era Histórico - do século XVII; Era histórica e científica - do século XVIII para o ano de 1789; Era Literária e Bibliofílica - 1790-1810; Era Artesanal 1810-1914; Era Técnica - de 1914 a meados do século XX (Malclès 1956).

A maioria desses estudos se limita a década de 1960. Contudo, fatos marcantes ocorreram no campo da política, economia, ciência e das tecnologias da informação e comunicação. Assim, com a finalidade de atualizar ou dar continuidade à historiografia da Bibliografia, o fluxograma a seguir ilustra a divisão que a literatura reporta e o acréscimo dado pelos estudos da área pelo pesquisador.

Figura 2 - Timeline da evolução da Bibliografia

\section{Historiografia da Bibliografia}

Historiografia da bibliografia, sinteticamente colocada nesse time line (linha do tempo)

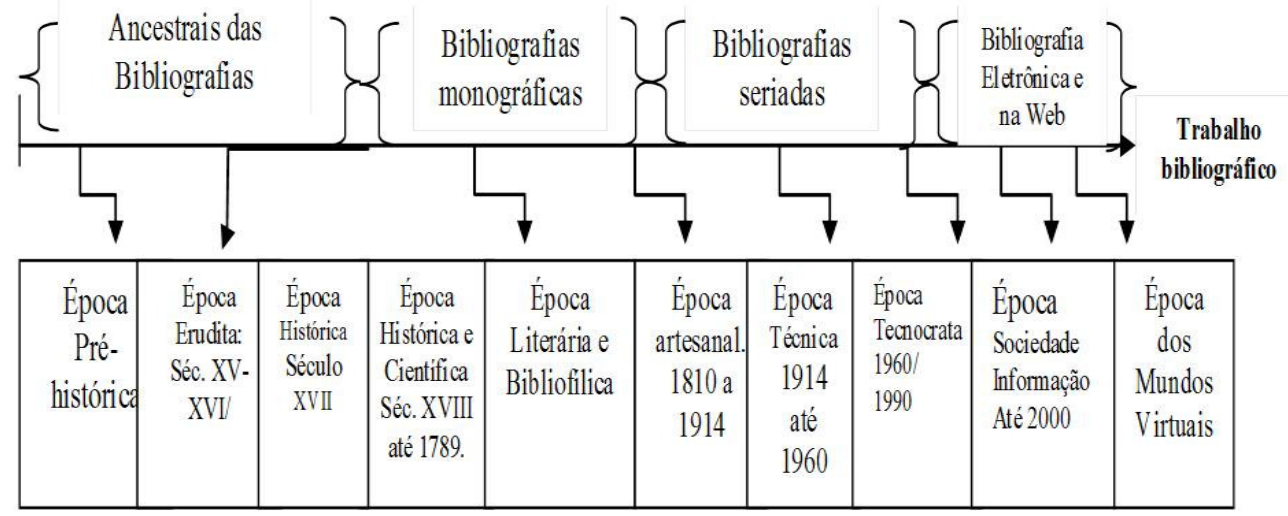

Fonte: Adaptado de Greg (1914), Besterman (1935); Malclès (1956); Figueiredo e Cunha (1967). 
De forma sumarizada, a história da bibliografia demonstra que 0 desenvolvimento do conhecimento do trabalho bibliográfico se alinha com o desenvolvimento de tecnologias de produção intelectual. As formas de organizar esse crescimento se materializam na Bibliografia. $O$ trabalho bibliográfico foi primeiro útil para bibliotecas monásticas; em seguida, para o comércio livreiro, depois, serviram para o ambiente acadêmico após reformas na educação e começou a ser preparado independente de bibliotecas e do comércio livreiro. Correspondências entre os dois levantamentos históricos são sintetizados no quadro a seguir:

Quadro 1 - Correspondências entre as pesquisas históricas com determinadas características

\begin{tabular}{|c|c|c|}
\hline Harmon & Malclès & Características \\
\hline Começos & Pré-histórica & $\begin{array}{l}\text { A maioria das bibliografias eram listas de obras de um } \\
\text { autor em uma biografia, por vezes chamados de ancestrais } \\
\text { da bibliografia. }\end{array}$ \\
\hline $\begin{array}{l}\text { Período } \\
\text { Médio }\end{array}$ & Pré-histórica & $\begin{array}{l}\text { O trabalho bibliográfico se ocupava das coleções em } \\
\text { bibliotecas monásticas cujos instrumentos de guarda foram } \\
\text { submetidos a algum tipo de padrão; e denominados por: } \\
\text { "Catálogo", "Bibliotheca','Index','Registrum 'ou' } \\
\text { Repertorium' }\end{array}$ \\
\hline $\begin{array}{l}\text { Período } \\
\text { Moderno }\end{array}$ & $\begin{array}{c}\text { Da Era Erudita à } \\
\text { Era Artesanal }\end{array}$ & $\begin{array}{l}\text { Com a invenção da imprensa, resultando em aumento na } \\
\text { produção de livros, a necessidade de registrar e controlar } \\
\text { bibliograficamente a efusão literária também aumentou. } \\
\text { Aparecimento de bibliografias impressas; comercial e } \\
\text { especializada em conteúdo, nacional e universal em seu } \\
\text { escopo. Produção de livros foi marcada pelo Período } \\
\text { Artesanal entre } 1500 \text { a } 1800 \text {. }\end{array}$ \\
\hline $\begin{array}{c}\text { Período } \\
\text { Contemporâ } \\
\text { neo }\end{array}$ & $\begin{array}{c}\text { Da Era Artesanal } \\
\text { à Era Técnica }\end{array}$ & $\begin{array}{l}\text { Até o início do Séc. XIX, a produção comercial da } \\
\text { bibliografia permanecia artesanal. O grande movimento } \\
\text { científico ao longo do século transformou as condições do } \\
\text { trabalho intelectual. Surgem os primeiros teóricos da } \\
\text { Bibliografia: S. Boulard, com o Traité élémentaire de } \\
\text { bibliographie, publicado em } 1805 \text { e C. F. Achard, com a } \\
\text { obra 'Cours élémentaire de bibliographie, de } 1806 \text {. No } \\
\text { início do século XX, a "nova bibliografia" tinha com bases } \\
\text { para os aspectos físicos do livro. A produção de livros foi } \\
\text { marcada pelo período industrializado, 1800-1950. Com as } \\
\text { organizações de documentação, bibliografias monográficas } \\
\text { e seriadas começaram a ser desenvolvidas independentes } \\
\text { do comércio livreiro e bibliotecas O ideal de controle } \\
\text { bibliográfico universal é aperfeiçoado com o } \\
\text { desenvolvimento das bibliografias nacionais. Na década de } \\
1950, \text { as bases de dados foram desenvolvidas pelo Bureau } \\
\text { of Census nos EUA. Em 1958, bibliografias estatísticas, } \\
\text { índices, passaram a medir a citação de periódicos } \\
\text { científicos. }\end{array}$ \\
\hline
\end{tabular}

Fonte: Adaptado de Malclès (1956) e Harmon (1998). 
Depois da impressa e em formato analógico, bibliografias também começaram a ser produzidos eletronicamente e, recentemente, no ambiente Web em amplas possibilidades de aplicação e uso estão situadas em diferentes contextos de aplicações, trazem enfrentamentos antigos e novos relacionados, por exemplo, à sobrecarga informacional e ao acesso à informação.

Os nomes atribuídos às épocas contemporâneas do trabalho bibliográfico, após 1960, são aqui inventivos no sentido de representarem, em parte, tanto o desenvolvimento tecnológico que estimulou a ampliação do trabalho bibliográfico quanto o aproveitamento dos fundamentos da Bibliografia em cada contexto histórico, a saber: Época Tecnocrata, 1960 até 1990; Época da Sociedade da Informação: 1990-2000; Época dos Mundos Virtuais: início do Século XXI.

\section{1 Época Tecnocrata}

Tecnocracia foi inicialmente uma forma de estrutura organizacional ou sistema de governo em que os tomadores de decisão seriam selecionados com base no conhecimento tecnológico (ELSNER JUNIOR, 1967). Embora a teoria da tecnocracia tenha começado no início do Século XX, na área de serviços de informação, suas características eram evidentes nos períodos entre 1960 a 1990.

Através da tecnocracia, havia a crença de que o excesso de informação poderia ser solucionado muitas vezes pela aplicação tecnológica. Coblans (1957) explica que, no século XIX a desordem crescente da literatura impedia o desenvolvimento da ciência. $O$ grande aumento do conhecimento registrado em diversos meios de comunicação, a inundação de impressos e ao crescente número de revistas científicas são causas da explosão documental.

De acordo com Coblans (1957), em pouco mais de cem anos, foram desenvolvidos três meios para facilitar o controle da situação: 1) os serviços de indexação e publicação de resumos baseados em bibliometria; 2) uso ostensivo de tecnologias de reprodução de 
substitutos para a informação original; 3) adaptação e aperfeiçoamento de máquinas para ajudar no controle dos fluxos de informação.

Esse período foi o início do processo de automação de bibliotecas e o desenvolvimento promissor de bases de dados que contribuíram para a sistematização do trabalho bibliográfico, ampliando a produção de bibliografias especializadas e dos periódicos de indexação e resumo (CENDÓN, 2003) e gerais ${ }^{26}$.

Em 1966, Markuson (1967, p. 261) em seu capítulo de revisão de literatura no Annual Review of Information Science and Technology discorreu sobre o estado da automação em bibliotecas e sistemas de informação. De acordo com a autora, a década de 1960 foi marcada pelo crescente interesse e atividades em automação em larga escala por parte de bibliotecas e centros bibliográficos nacionais. Esse período foi marcado pela problemática sobre: o que converter tanto em termos de coleções, catálogos e bibliografias quanto em termos de serviços automatizados.

Bibliotecas se beneficiaram com as tecnologias computacionais que emergiam e melhoravam suas atividades, tais como: Catalogação Cooperativa, Serviços de Disseminação Seletiva da Informação e Bibliografias retrospectivas (ALENTEJO, 2014a). Na década de 1970, o programa Controle Bibliográfico Universal, da Unesco e IFLA, visava reunir e tornar disponíveis os registros da produção bibliográfica de todos os países, em uma rede internacional de informação, considerando a identificação, localização e forma de obtenção do documento (ROBERTS, 1996), de modo alinhado aos objetivos do trabalho bibliográfico.

\footnotetext{
${ }^{26}$ Por exemplo, na Biblioteca Nacional (BN), sob a direção de Jannice Monte-Mór (1971-1979), o Centro de Informática do Ministério da Educação e Cultura (CIMEC) elaborou análises das rotinas de controle dos periódicos, originando projetos de execução do catálogo e do inventário do acervo de publicações periódicas da Biblioteca Nacional. Simultaneamente, permitiu os meios de controlar o registro da bibliografia brasileira corrente, dando, como produto imediato, a primeira publicação por computador CONSELHO REGIONAL DE BIBLIOTECONOMIA 7ạ REGIÃO, 2005).
} 
Bibliografias seriadas, gerais e especializadas, começaram a ser produzidas através de recursos do computador e salvaguardadas em suportes eletrônicos. Como consequência, as bases de dados bibliográficos e os periódicos de indexação e resumos foram expandidos. Em todas as áreas, atividades tecnocratas e suas ideias foram o fator crucial por trás da disseminação da tecnologia moderna e em grande parte do conceito ideológico da Sociedade da Informação (ELSNER JUNIOR, 1967).

\section{2 Época da Sociedade da Informação}

Considerando a Sociedade da Informação como uma noção orientada para a criação, distribuição, utilização, integração e manipulação da informação como uma atividade econômica, política e cultural significativa, o trabalho bibliográfico se tornou mais socialmente consciente e desejável.

Sob os diferentes formatos, disposição e organização baseada em sistemas de recuperação de informação, novas interfaces de arquitetura de informação e as formas de acesso à informação, o trabalho bibliográfico ganhou novas frentes para servir à sociedade $\mathrm{e}$ melhorar os propósitos sociais da bibliografia (ALENTEJO, 2014b; HARMON, 1998; REYES GÓMEZ, 2010).

A popularização dos computadores pessoais e das novas mídias e modos de registros com Tecnologias da Informação (CD-ROM, disquete, DVD, documentos digitalizados etc.), e essencialmente, a popularização da Internet pela World Wide Web, desde 1991, tem democratizado o trabalho bibliográfico ao permitir sua produção por indivíduos e por qualquer organização (ROWLEY, 2002).

Nesse período, as Bibliotecas Digitais surgiram com serviços de informação e catálogos institucionais compartilhadas na Internet, e através de bases de dados sofisticadas atuaram como produtos bibliográficos, com o fornecimento e acesso direto aos documentos e diretórios de todos os tipos de informação (URS, 2001). 
O comércio pela Internet ganhou força, e o mercado do livro se expandiu, pois, editoras ampliaram serviços e divulgação de seus catálogos na rede. O desenvolvimento das tecnologias da informação e sua interferência nos processos de comunicação humana consolidou a Sociedade da Informação como o principal fenômeno global, cuja lógica é a produção em larga escala a partir da mudança de paradigma da era industrial para a valorização do ambiente baseado em informação.

$\mathrm{O}$ avanço das Bibliotecas (eletrônicas, virtuais, digitais ${ }^{27}$ ) rumo à participação na Sociedade da Informação bem como no seu desenvolvimento recebe influências da tecnologia, pela forma como uma nação e organizações conduzem o enfrentamento às questões advindas da globalização, padrões e qualidade, direitos de propriedade intelectual, segurança, preservação e controle bibliográfico.

Nesse contexto, o trabalho bibliográfico também se amplia. $O$ planejamento, a organização e a distribuição das coleções digitais na rede configuram-se em atividades que requerem fundamentos, métodos e técnicas seculares da Bibliografia.

\section{3 Época dos Mundos Virtuais}

A expansão da Bibliografia se observa, sobretudo, quando se verifica o desenvolvimento da Web, com o uso das novas tecnologias na Internet que vaticinam a preservação de artefatos informacionais digitais em longo prazo à manutenção e à conservação adequadas para manter a capacidade de sua reprodução de modo a garantir o acesso intacto à informação para uso das gerações futuras (CRIADO, 2015).

O versionamento Web 2.0 ou Web Social, no início dos anos 2000, ofereceu uma arquitetura de participação à coletividade. Essa versão Web, compreendida como Web sintática (ou Web de

\footnotetext{
${ }^{27}$ Urs (2001), Rowley (2002) e Gonçalves (2004), entre outros, explicam que definições sobre biblioteca eletrônica, digital ou virtual se situam em miríades de significados, essencialmente, operacionais; não havendo conceitos consolidados na literatura especializada.
} 
Documentos) (CARVALHO, 2014); na qual o processo de interpretação dos conteúdos disponíveis geralmente é deixado para os usuários que tanto podem ser consumidores quanto geradores de conteúdo.

De acordo com Carvalho (2014), dinamicidade, participação e interação são as chaves para esta fase da Web. Elas são necessárias porque o usuário pode interagir de forma colaborativa, deixando a Internet participativa entre pessoas de qualquer lugar do mundo e possibilitando a construção coletiva do conhecimento. Sua aplicação online deve aproveitar ao máximo os efeitos de rede e da inteligência coletiva. O grau de interação proporcionada pela Web é baseado na comunicação.

Já a promessa de nova versão da Internet, a denominada Web Semântica ou Linked Open Data, foca estruturas de dados e os planos para criar outro nível de busca de informação, oferecendo resultados customizados de acordo com necessidades do usuário (POLLOCK, 2010).

A sua realização será resultado da associação de informações, experiências e conhecimentos adquiridos através da Web $2.0 \mathrm{com}$ a tecnologia semântica. Este versionamento tem por objetivo proporcionar o poder de análises de muito mais informação com menos esforço e resultados precisos (POLLOCK, 2010; CARVALHO, 2014). Nesse sentido, o grau de sua interação com o usuário é baseado na precisão da recuperação da informação.

Com a expansão do espaço digital, os surgimentos de diferentes objetos de informação, o crescente número de publicações e os modos de sua produção mudam a natureza de sua representação, distribuição e acesso, que de modo coletivo compõe assim, novos campos de investigação científica para a Bibliografia.

Considerando os sistemas de informação baseados na Web, além de mudança de comportamento do usuário e a capacidade de acessar vários conjuntos de modo remoto, sem barreiras, fatores explícitos dos fundamentos da Bibliografia se intensificaram nessa era 
digital: a sobrecarga de informações, novos padrões descritivos de informações, a diversidade de usuários e desafios no ambiente digital tais como, preservação e probidade intelectual ${ }^{28}$ (PARENT, 2007).

Sob esses contextos, o trabalho bibliográfico pode ser construído em muitas possibilidades, tais como: Bibliografia Nacional e mercado editorial na Web. Ao longo do tempo, a bibliografia nacional corrente (PARENT, 2007) e o mercado de livros (ROWLEY, 2002, LANKES et al. 2007) extraíram benefícios do trabalho bibliográfico de muitas maneiras, como a aplicação dos princípios técnicos que regem o trabalho bibliográfico.

A bibliografia nacional online pode existir "como uma base de dados separada ou pode ser parte do catálogo online nacional de uma Biblioteca Nacional" (PARENT, 2007, p. 4), e de modo semelhante, as editoras constituem suas bibliografias comerciais online, agregando serviços ao usuário em sítios na rede.

Diante dos desafios que as recentes tecnologias na plataforma Web impõem às agências bibliográficas, tais como a facilidade que o usuário tem de acesso à informação, a diversidade de usuários e a oferta de sistemas informacionais, o atual modelo de controle bibliográfico nacional tende a mudar seu paradigma, de "o que é" para o que ele precisa ser para os usuários, agora e no futuro (PARENTS, 2007).

A maioria dos sistemas de recuperação de informação dentro das bibliotecas nacionais online, como o catálogo online e bibliografia nacional se posicionam como a interação de mão única com os usuários. No entanto, enquanto sendo redes participativas, bibliografias e catálogos nacionais poderiam reforçar o seu papel, pois, as condições tecnológicas existentes podem ser considerados na arquitetura das bibliografias nacionais de forma a obter proveitos da inteligência coletiva

\footnotetext{
${ }^{28}$ Numa perspectiva técnica que fundamenta o sucesso de uma bibliografia, Placer (1955, p. [7]) explica a probidade intelectual é princípio conectado com o da verificação e planejamento bibliográficos de forma a garantir a crítica intelectual.
} 
da Web 2.0 (LANKES et al., 2007) e para o controle bibliográfico nacional (PARENT, 2007).

A Bibliografia Nacional baseada na Web pode ser projetada para ser um modelo de interação em via de mão dupla, isto é, participativo. As aplicações podem ser diversas, por exemplo, hospedagem de blogs e wikis para comunidades de usuários; uso de software livre de código aberto disponível para criar versões de bibliografias Wikipédia; a criação de espaços de encontros virtuais coletivos. Algumas dessas sugestões implicam na ação direta do usuário, como a manipulação e alteração de dados no sistema, exigindo, portanto, níveis de confiabilidade.

Considerando que muitos dos usuários se tornaram acostumados com a ideia de funções e níveis de autoridade em muitas outras configurações online, a tecnologia existente, por exemplo, permitiria a introdução de sistemas de mérito, de modo a tirar proveito de redes colaborativas de sítios na Web (LANKES et al., 2007), tal como ocorre com a Amazon.com, LibraryThing, eBay, Barnes \& Noble etc.

A Bibliografia relaciona-se também com tendências de bibliotecas digitais, como o modelo gerencial (GONÇALVES, 2004) e a federação de dados. Seu princípio consiste em registros de dados estruturados que são publicados na Web em formatos reutilizáveis e acessíveis remotamente em qualquer formato de Sistema de Recuperação da Informação (FERREIRA; SOUTO, 2006).

As bibliotecas digitais começaram a experimentar 0 desenvolvimento de serviços e produtos com tecnologias Linked Data, tais como: realização de dados aberto em RDF; fusão e agregação de conjuntos de dados e novas aplicações para seus usuários finais, fornecendo serviços bibliográficos para desenvolvedores dentro e fora do domínio da biblioteca (PRASAD; MADALLI, 2008). Novos modelos de bibliotecas digitais e padrões como FRBR e RDA estão sendo inspirados por RDF, tais como: a Biblioteca Nacional da França e da Library of Congress Bibliographic Framework Initiative (GODBY; DENENBERG, 2015). 
Uma vez que, Bibliografias comerciais podem ser divididas em duas categorias: por artefatos impressos (e analógicos) e digitais, similar ao Google Livros, bibliografias comerciais podem ser compartilhadas em serviços especializados de busca aos conteúdos de livros.

Como serviços de valor agregado, editoras podem integrar bibliografias nacionais online aos catálogos, permitindo aos usuários 0 acesso a bases de dados de agências bibliográficas. Sob o ponto de vista do usuário, a pesquisa federada permitiria múltiplas fontes de informação a serem pesquisadas, ao mesmo tempo. Isso inclui bibliografias online, catálogos de bibliotecas e bases de dados comerciais.

\section{$5 \quad$ DISCUSSÃO}

A historiografia da Bibliografia permite compreender que a polifonia acerca do seu termo não autoriza a miríade de significados decorrente da falta de seu ensino nos cursos de Biblioteconomia, mas, sua falta compromete seu desenvolvimento.

Bibliografia é uma parte do conhecimento científico cuja importância e estudo não se limitam ao seu passado e aos artefatos impressos (FONSECA, 1979; GASKELL, 1972). Tampouco não se esgota com as tecnologias que foram úteis e as que são utilizadas para a sua produção, aplicação de sua função social.

Ao contrário, a história contada revela que o desenvolvimento das tecnologias de produção intelectual coaduna-se com o desenvolvimento do conhecimento. Os modos de se organizar esse crescimento se materializam na Bibliografia, tendo de seus fundamentos a ampliação de possibilidades de gerência à: produção, transmissão e acesso aos conteúdos intelectuais em variados suportes.

Isso sugere que no futuro, o trabalho bibliográfico não será sufocado pelas tecnologias. Se no passado elas foram úteis para seu aperfeiçoamento, logicamente, continuarão a ser. Pois, as aplicações da Bibliografia se referem aos seus fundamentos: controle bibliográfico, a 
arte do livro e de outros artefatos, e do próprio desenvolvimento do conhecimento humano (SIMÓN DÍAZ, 1971).

Tal como explica Placer (1955), não há trabalho intelectual de espécie alguma, neste estágio do conhecimento, sem o trabalho bibliográfico, e este é fruto do empreendimento intelectual que visa garantir a obtenção dos elementos essenciais à descrição bibliográfica, à avaliação da consistência e confiabilidade na produção do trabalho bibliográfico, de alguma pesquisa bibliográfica ou ainda a alguma consulta a um 'catálogo' ou a qualquer tipo de bibliografia.

Seu passado, presente e futuro perpassam por contextos, contingências históricas e culturais, necessidades humanas concretas do trabalho bibliográfico, de suas técnicas e de suas metodologias; e, sobretudo, isso expõe a ampliação das funcionalidades da Bibliografia no contínuo cenário social e tecnológico.

\section{CONSIDERAÇÕES FINAIS}

Os caminhos contados e vividos da Bibliografia se materializam no trabalho bibliográfico como atividade intelectual, secular do seio das sociedades, movido pelo desejo e necessidade de controle sobre o conhecimento em registros descritivos destinados a várias finalidades $\mathrm{e}$ usos. Isso se traduz nas funções sociais da Bibliografia: favorecer o controle bibliográfico, a ampliação da descrição dos artefatos informativos e divulgação e a preservação do conhecimento registrado.

Das bibliografias monográficas sucederam as seriadas. Daquelas de cobertura nacional, o trabalho bibliográfico se ampliou para o nível internacional, com alcance global. Depois, do formato impresso e analógico para o meio eletrônico. E, da simples enumeração com a sistematização dos conteúdos, as bibliografias adquiriram a função de indicadores, úteis para o desenvolvimento científico. E, por fim, com as tecnologias na Internet, as redes de conhecimento ampliaram a produção e uso do trabalho bibliográfico, de um passado restrito a poucos para um futuro aberto à coletividade. 
Pois, no atual estágio da humanidade, o trabalho bibliográfico pode ampliar sua distribuição, diversificar suas aplicações e alcançar números de usuários de modo jamais imaginado até a metade do Século XX.

Pela análise historiográfica, seus caminhos indicam que 0 campo de estudo é inesgotável, porque, pesquisas sobre o passado da bibliografia englobam aspectos teóricos acumulados e o seu presente expõe muitas possibilidades para seu futuro.

\section{REFERÊNCIAS}

ALENTEJO, Eduardo. A bibliografia material: o livro inteligível. In: FÓRUM INTERNACIONAL SOBRE LIVROS ANTIGOS, RAROS E ESPECIAIS, 2014, Rio de Janeiro. Vídeos... Rio de Janeiro: UNIRIO, 2014a. 1 vídeo. Disponível em: <http://youtu.be/EwCdo4VMOMk>. Acesso em: 29 nov. 2014.

Redes participativas: a biblioteca como conversação. In: COLÓQUIO INTERNACIONAL DE ARQUITETURA DA INFORMAÇÃO E MULTIMODALIDADE, 3., 2014, Brasília. Anais eletrônicos... Brasília: UnB/FIOCRUZ, 2014b. Disponível em: <http://www.regiimento.com.br/iiiciaim>. Acesso em: 2 dez. 2014.

ALENTEJO, Eduardo; PINHEIRO, Ana Virginia. The memory of brazilian librarianship: past and present of the future. In: IFLA INTERNATIONAL CONFERENCE, SATELLITE MEETING, HISTORY OF LIBRARIANSHIP, 2014, Lyon. Anais eletrônicos... Lyon: IFLA Library Repository, 2014. Disponível em: <http://histlibr2014.sciencesconf.org/ user/submissions?docid=29496>. Acesso em: 1 dez. 2014.

ALFARO LOPEZ, Héctor Guillermo. La bibliografía: historia de una tradición. Investigación Bibliológica, Ciudad de México, v. 25, n. 55, 2011. Disponível em: <http://www.scielo.org.mx/scielo.php?script=sci_arttext\&pid=S0187358X2011000300012\&lng=es\&nrm=iso>. Acesso em: 7 jul. 2014.

ARAÚJO, Zilda Galhardo de. Guia de bibliografia especializada. Rio de Janeiro: Associação Brasileira de Bibliotecários, 1969. 
BASTO, Patrícia Lopes. Bibliografia de teses sobre música. Revista Portuguesa de Musicologia, Lisboa, p. 63-136, 1999. Disponível em: <http://www.rpm-ns.pt/index.php/rpm/article/viewFile/136/140>. Acesso em: 14 nov. 2014.

BEAUDIQUEZ, Marcelle. Guide de bibliographie génerále: méthodologie et pratique. München: K. G. Saur, 1989.

BELANGER, Terry. Descriptive bibliography. In: PETERS, Jean. Book collecting: a modern guide. New York: Bowker, 1977. p. 98-115.

BESTERMAN, Theodore Deodatus Nathaniel. The beginnings of systematic bibliography, London: Oxford University Press, 1935.

BRADFORD, Samuel C. Documentação. Rio de Janeiro: Fundo de Cultura, 1953.

CARVALHO, Éder. Web 2.0: a primeira evolução da Internet.

Hiperbytes. 2014. Disponível em: <http://hiperbytes.com.br/geral/web-20-a-primeira-evolucao-da-internet/>. Acesso em: 2 dez. 2014.

CASE, Donald O. Looking for information. $3^{\text {rd }}$ Ed. Bingley: Emerald Group, 2012.

CENDÓN, Beatriz Valadares. Serviços de indexação e resumo. In: CAMPELLO, Bernadete Santos; CENDÓN, Beatriz Valadares; KREMER, Jeannette Marguerrite. (Org.). Fontes de Informação para pesquisadores e profissionais. Belo Horizonte: UFMG, 2003. p. 217248.

COBLANS, Herbert. Introdução ao estudo de documentação. Rio de Janeiro: DASP, 1957. (Ensaios de Administração, n. 8).

COBLANS, Herbert. National bibliographical centre in Brazil. Ciência da Informação, Brasília, v.19, n. 1, p. 91-101, jan./jun. 1990. Disponível em: <http://revista.ibict.br/index.php/ciinf/article/view/1293/927>. Acesso em: 14 maio 2014.

CONDIT, Lester. Bibliography in its prenatal existence. Library

Quartely, London, n. 7, p. 564, Oct. 1937.

CONSELHO REGIONAL DE BIBLIOTECONOMIA 6ª REGIÃO. Cursos. Disponível em: <http://www.crb6.org.br/carreira.php>. Acesso em: 1 mar. 2015

CONSELHO REGIONAL DE BIBLIOTECONOMIA 7ª REGIÃO. Palavras sobre Jannice Monte-Mor. Boletim CRB-7, v. 30, n. 3, jul./set. 2005. Disponível em: <http://crb7.org.br/PDF/Boletins/20050709.pdf>. Acesso em: 1 mar. 2015. 
CRIADO, Miguel Ángel. Rumo a uma era digital obscura? 1 mar. 2015. Disponível em:

<http://brasil.elpais.com/brasi//2015/02/27/tecnologia/1425053335_2885 38.html>. Acesso em: 1 mar. 2015.

CRUZ, Jane Veiga Cezar da; BECKMANN, Clodoaldo Fernando Ribeiro. Bibliografia: um esboço histórico. Belém: EDUFPA, 1995.

DUNKIN, Paul S. Bibliography: tiger or fat cat? Hamden: Archon Books, 1975.

ELSNER JUNIOR, Henry. Technocrats, prophets of automation. Syracuse: Syracuse University Press, 1967.

FERREIRA, Sueli Mara S. P.; SOUTO, Leonardo Fernandes. Dos sistemas de informação federados à federação de bibliotecas digitais. Revista Brasileira de Biblioteconomia e Documentação, São Paulo, v. 2, n. 1, p. 23-40, jan./jun. 2006.

FIGUEIREDO, Laura Maia de; CUNHA, Lélia Galvão Caldas da. Curso de bibliografia geral para uso dos alunos das escolas de biblioteconomia. Rio de Janeiro: Record, 1967.

FIGUEIREDO, Nice (Coord.). O ensino de biblioteconomia no Brasil. Brasília: Ministério da Educação e Cultura, 1978

FONSECA, Edson Nery da. A Bibliografia como ciência: da crítica textual à bibliometria. Revista Brasileira de Biblioteconomia e Documentação, São Paulo, v. 12, n. 1/2, p. 29-38, jan./jun. 1979.

Bibliografia brasileira corrente: evolução e estado atual do problema. Revista Ciência da Informação, Rio de Janeiro, v. 1, n. 1, p. 9-14, 1972.

FREER, Percy. Bibliography and modern book productions. Johannesburg: Witwatersrand University Press, 1954.

GASKELL, Philip. A new Introduction to Bibliography. New york: Oxford University Press, 1972.

GODBY, Carol Jean; DENENBERG, Ray. Common ground: exploring compatibilities between the linked data models of the Library of Congress and OCLC. Dublin: Library of Congress, 2005.

GONÇALVES, M. A. Streams, structures, spaces, scenarios, and societies (5S): a formal digital library framework and its applications. Blackburg: Polytechnic Institute and State University, 2004.

GREG, Walter W. What is a bibliography. Transactions of the bibliographical society, London, n. 12, p. 4-53, 1914. 
HARMON, Robert B. Elements of bibliography. $3^{\text {rd }}$. London: Scarecrow Press, 1998.

Elements of bibliography. London: Scarecrow Press, 1981.

KATZ, William. Introduction to reference work. 6th ed. New York: Mc Graw-Hill, 1992.

KOHLER, Relinda. Bibliografia nacional: uma co-responsabilidade da classe bibliotecária. Revista da Escola de Biblioteconomia da UFMG, Belo Horizonte, v. 6, n. 2, p. 185-195, set. 1977.

LANKES, R. David, et al. Participatory networks: the library as conversation. Information Research, London, v. 12, n. 4, p. 1-8, 2007. Disponível em: <http://www.informationr.net/ir/12-4/colis05.html>. Acesso em: 4 nov. 2014.

LIMA, André (Coord.). Código florestal: por um debate pautado em ciência. Belém: Instituto de Pesquisa Ambiental da Amazônia, 2014. Disponível em: <http://www.ipam.org.br/biblioteca/livro/Estudo-do-Ipammergulha-na-producao-cientifica-existente-para-entender-importanciadas-florestas/761 >. Acesso em: 3 dez. 2014

MALCLÈS, Louise Noëlle. La bibliographie. Paris: Presses Univesitaires de France, 1956.

MALCLÈS, Louise Noëlle. Les sources du travail bibliographique. Paris: Minard, 1950.

France, 1963

Manuel de bibliographie. Paris: Press Universitaires de

MARKUSON, Barbara Evans. Automation in Libraries and Information Centers. Annual Review of Information Science and Technology, New York, v. 2, 1967, p. 255-309.

MCCRANK, Lawrence J. Analytical and historical bibliography: a state of the art review. Annual Report of the American Rare, Antiquarian and Out-of-Print Book Trade, New York, p. 175-185, 1979.

MCKERROW, Ronald B. Introducción a la bibliografía material. Madrid: Arco/Libros, 1998.

MENOU, Michel; GUINCHAT, Claire. Introdução geral às ciências e técnicas da informação e documentação. 2. ed. Brasília: IBICT, 1994.

MOREIRA, I. de C. Os primórdios do caos determinístico. Ciência Hoje, Rio de Janeiro, v. 14, n. 80, p. 11-16, 1992. 
PARENT, Ingrid. The Importance of National Bibliographies in the Digital Age. In: WORLD LIBRARY AND INFORMATION CONGRESS: IFLA GENERAL CONFERENCE AND COUNCIL, 73 ${ }^{\text {rd }}$, 2007, Durban.

Proceedings... [Paris]: WLIC, 2007. p. 1-10.

PENSATO, Rino. Curso de bibliografia: Guía para la compilación y uso de repertórios bibliográficos. Gijón: Trea, 1994.

PINHEIRO, Ana Virgínia. (Org.). Livros raros de biblioteconomia: a memória científica da Biblioteca Nacional brasileira: catálogo. Rio de Janeiro: Fundação Biblioteca Nacional. 2013. Disponível em:

$<$ http://biblioo.info/wp-

content/uploads/2013/09/LivrosRarosDeBiblioteconomia-Catalogo.pdf>. Acesso em: 11 jun. 2014.

PLACER, Xavier. A bibliografia e sua técnica. Rio de Janeiro: MEC/Serviço de Documentação, 1955.

POLLOCK, Jeffrey T. Web semântica para leigos. Rio de Janeiro: Alta Books, 2010.

PRASAD, Ard; MADALLI, Devika P. Faceted infrastructure for semantic digital libraries. Library Review, Wales, v. 57, n. 3, p. 225-234, 2008.

PRITCHARD, Alan. Statistical bibliography or bibliometrics? Journal of Documentation, London, v. 25, n. 4, p. 348-349, Dec. 1969. Disponível em:

<https://www.academia.edu/598618/Statistical_bibliography_or_bibliome trics>. Acesso em: 2 jul. 2014.

REUBEN, Aldridge Guild. Bibliography as a science. The Library Journal, New York, v. 4, n. 5, p. 67-69, 1937.

REYES GÓMEZ, Fermín de los. Manual de bibliografía. Madrid: Catalia, 2010.

ROBERTS, Winston D. O que é CBU? Anais da Biblioteca Nacional, Rio de Janeiro, v. 114, p. 149-171, 1996.

ROWLEY, Jennifer. A biblioteca eletrônica. Brasília: Briquet de Lemos, 2002.

SERRAI, Alfredo. Biblioteche e bibliografia: vademecum disciplinare e professionale. Roma: Bulzoni, 1994.

SHERA, J. H.; EGAN, M. E. Foundations of a theory of bibliography. Library Quarterly, Chicago, v. 22, n. 2, p. 125-137, 1952. 
SHERA, Jesse H.; EGAN, Margaret E. Exame do estado atual da biblioteconomia e documentação. In: BRADFORD, Samuel C.

Documentação. Rio de Janeiro: Fundo de Cultura, 1953. p. 16-37.

Foundations of theory of bibliography. In: BRENNI, Vito J.

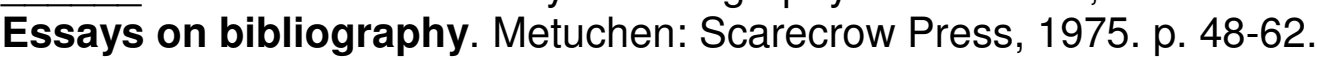

SIMÓN DÍAZ, José. La bibliografía: conceptos y aplicaciones.

Barcelona: Planeta, 1971.

SIRKKA HAVU. Conrad Gesner: father of bibliography: Bibliotheca Universalis, how to organize the caos. In: SATELLITE MEETING TO THE WORLD LIBRARY AND INFORMATION CONGRESS, 71 ${ }^{\text {st }}$., 2005, Järvenpää. Proceedings... Järvenpää: WLIC, 2005. Não paginado.

SISTEMA NACIONAL DE AVALIAÇÃO DA EDUCAÇÃO SUPERIOR SINAES. Instrumento de avaliação institucional externa. 2010.

Disponível em: <http://portal.inep.gov.br/superior-sinaes>. Acesso em: 10 maio 2014.

URS, Shalini. Pratical digital libraries: an overview. In: JOINT WORKSHOP ON DIGITAL LIBRARIES, Mysore. Proceedings... Mysore: United States Educational Foundation in India, DRTC/Indian Statistical Institute, 2001. Não paginado.

VARRY, Dominique. Qu'est-ce que la bibliographie matérielle? Paris, 2011. Disponível em: <http://dominique-varry.enssib.fr/node/31>. Acesso em: 10 dez. 2013.

WILLIAMSON, Derek. Bibliography: historical, analytical and descriptive: an examination guidebook. London: Clive Bingley, 1967.

WORKING GROUP ON THE FUTURE OF BIBLIOGRAPHIC CONTROL. Report of The Library of Congress working group on the future of bibliographic control. Washington: Library of Congress, 2008. Disponível em: <http://www.loc.gov/bibliographicfuture/news/lcwg-ontherecord-jan08-final.pdf>. Acesso em: 10 maio 2014.

ZOLTOWSKI, Victor Stanislas Adam. Le cycles de la création intelectuelle et artistique. Paris: Presses Universitaires de France, 1955.

Title

Bibliography: from the ancient paths to the current paths 


\section{Abstract:}

Introduction: This article analyzes Bibliography with reference to its historiography.

Objective: It analyzes the concepts that underlie and validate Bibliography as a field of knowledge to answer: what are the ways of its story told and its current history that legitimate it as a current field of scientific interests?

Methodology: From the historiographical method, it discusses the current state Bibliography of education in Brazil. Through literature review explains its division into branches and discusses their history according to historical contours of which involve technological aspects of knowledge production.

Results: The research updates the historiographical continuity of Bibliography and adds reflections on the times of bibliographic work in the digital age. The results point to the development of Bibliography, both as a product and service, as a scientific area in constant development.

Conclusions: Through historiographical analysis, the Bibliography's paths indicate that the field of study is inexhaustible. Researches on the past of accumulated bibliography include theoretical aspects that remain in the current time and its actuality exposes many possibilities for its future. Bibliographies in web environment allow the expansion of understanding regarding access and use of information by the possibility of using technological resources capable of improving their social functions of access to knowledge in different scopes.

Keywords: Brazilian education on bibliography. Fundamentals of bibliography. Branches of bibliography. Historiography of Bibliography. Bibliography in the digital age.

\section{Titulo}

Bibliografía: de caminos antiguos a las formas actuales

\section{Resumen}

Introducción: Este artículo analiza Bibliografía con referencia a su historiografía.

Objetivo: Se analizan los conceptos que subyacen y validan Bibliografía como un campo de conocimiento para responder: ¿cuáles son los caminos de la historia contada y su historia actual que legitiman como un campo actual de los intereses científicos?

Metodología: A partir de la revisión de la literatura, el presente trabajo adopta el método historiográfico.

Resultados: En él se explica la división de la Bibliografía sobre ramas y escuelas de pensamiento y su historiografía de acuerdo con contornos históricos de los cuales se refiere a aspectos tecnológicos de la producción de registros de conocimiento impreso. La investigación se actualiza la continuidad historiográfica de Bibliografía y añade reflexiones sobre los tiempos de trabajo bibliográfico en la era digital. Los resultados apuntan al desarrollo de la Bibliografía, tanto como un producto y servicio, como un área científica en constante desarrollo.

Conclusiones: A través del análisis historiográfico, caminos de la bibliografía indican que el campo de estudio es inagotable. Las investigaciones sobre el 
pasado de la bibliografía acumulada incluyen aspectos teóricos que se mantienen en el presente y su actualidad expone muchas posibilidades para su futuro. Concluye que las bibliografías en entorno web permiten la expansión de entendimiento relativo al acceso y uso de la información por la posibilidad de utilizar recursos tecnológicos capaces de mejorar sus funciones sociales de acceso al conocimiento en diferentes ámbitos.

Palavras clave: Enseñanza brasileña de bibliografía. Fundamentos de la bibliografía. Ramas de bibliografía. Historiografía de la bibliografía. Bibliografía en la era digital.

Recebido em: Abril de 2015

Aceito em: Julho de 2015 